\title{
OS EFEITOS DO ABUSO SEXUAL NA SAÚDE MENTAL DOS ADOLESCENTES E SUAS RELAÇÕES COM OS ESTILOS PARENTAIS ${ }^{1}$
}

\author{
THE EFFECTS OF SEXUAL ABUSE IN TEENAGERS MENTAL HEALTH AND \\ ITS RELATIONS WITH PARENTAL STYLES
}

\section{Noelise da Rosa Pereira ${ }^{2}$, Suéllen Flôres Machado ${ }^{3}$, Tyelli de Bittencourt Schott ${ }^{4}$, Fernanda Pires Jaeger ${ }^{5}$ e Janaína Pereira Pretto Carlesso ${ }^{6}$}

\section{RESUMO}

Este artigo apresenta uma discussão sobre os efeitos do abuso sexual na saúde mental dos adolescentes e suas relações com os estilos parentais. O presente artigo tem como objetivo verificar os efeitos do abuso sexual na saúde mental dos adolescentes e suas relações com os estilos parentais. Trata-se de um estudo descritivo de abordagem qualitativa e caráter exploratório, uma vez que visa propiciar mais informações a respeito do abuso sexual. Este estudo de natureza básica pesquisou nas bases de dados como Scielo, BVS, PubMed e Google Acadêmico. A análise bibliográfica foi realizada no período de setembro à outubro de 2020. Por meio dos descritores violência sexual, jovens, bem-estar mental e práticas parentais, foram selecionados artigos científicos, monografias e dissertações nacionais que contemplem o tema estudado. A pesquisa buscou identificar na literatura os efeitos do abuso sexual nos aspectos emocionais e sociais dos adolescentes, bem como elucidar a relação dos estilos parentais com a maior predisposição de certos adolescentes de sofrerem abuso sexual. Segundo os dados analisados, encontrados na literatura científica sobre o assunto, conclui-se que as consequências à saúde mental dependem tanto do grau de violência sofrida quanto dos recursos psíquicos próprios do jovem. Além disso, conclui-se também que práticas parentais que se caracterizam pelo afeto e carinho, ou seja, o modelo parental participativo, configuram-se como fator protetor ao abuso sexual entre os adolescentes.

Palavras-chaves: Bem-estar mental; Jovens; Práticas parentais; Violência sexual.

\section{ABSTRACT}

This article apresents a discussion about the effects of sexual abuse in teenagers mental health and its relations with parental styles. The present article aims to check the effects of sexual abuse in teenagers mental health and its relations with parental styles.. It's a descriptive study with qualitative approach and exploratory character, once it aims provide more information about sexual abuse. This basic study searched databases such as Scielo, BVS, PubMed and Academic Google between September and October 2020. The bibliographic analysis was carried out from September to October 2020. Through the descriptors sexual violence, teenagers, mental welfare and parental practices, there were selected scientific articles, monographs and national dissertations that contemplate the studied topic. The research sought to identify in the literature the effects of sexual abuse on the emotional and social aspects of teenagers, as well as elucidate the relation between parental styles and the greater predisposition of certain teenagers to suffer sexual abuse. According to the data analyzed, found in the literature about the subject, it's concluded that the mental health consequences depend on the 1 Trabalho acadêmico.

2E-mail: noelisepereira@hotmail.com

3 E-mail: suellenfloresmachado@gmail.com

4 E-mail: tyellib@gmail.com

5 E-mail: fernandajaeger19@gmail.com

6 E-mail: janaina.carlesso@ufn.edu.br 
degree of violence suffered and the psychological resources of the teenager. Besides that, it's also concluded that parental practices that are characterized by affection, wich means, the participatory parental model, it's configured as a protective factor against sexual abuse among teenagers.

Keywords: Mental welfare; Parental practices; Sexual violence; Teenagers.

\section{INTRODUÇ̃̃O}

O Estatuto da Criança e do Adolescente visa a proteção integral dos direitos da criança e do adolescente a fim de colocá-los a salvos de qualquer forma de discriminação, exploração e violência (BRASIL, 1990). No entanto, infelizmente, o abuso sexual continua sendo uma realidade no cotidiano de muitas pessoas, sendo considerado um grave problema de saúde pública. De acordo com o relatório do Fundo das Nações Unidas para a Infância (UNICEF), publicado no ano de 2017, a cada sete minutos uma criança ou adolescente é vítima de violência e, aproximadamente, 15 milhões de adolescentes do sexo feminino, entre 15 e 19 anos, foram vítimas de relações sexuais ou outros atos sexuais forçados. Dessa forma, segundo dados do Disque 100, a violência sexual contra criança e adolescente foi o quarto tipo de violência mais recorrente no país em 2017 (MIRANDA et al., 2019). Nesse sentido, torna-se evidente que a violência sexual ocorre em todo o mundo e atinge milhares de meninos e meninas cotidianamente, comprometendo sua qualidade de vida e seu desenvolvimento físico, emocional e intelectual (SANTOS, 2009).

Juntamente com a exploração sexual, o abuso é identificado como uma das principais formas de violência sexual. Nesse sentido, ele pode ser definido como qualquer contato ou interação de um indivíduo com uma criança e/ou adolescente, obrigando-o a atos e jogos eróticos ou sexuais, através de ameaças, subornos e violência física, com o objetivo de satisfazer suas necessidades sexuais (SOUZA et al., 2019). Esse tipo de violência pode envolver relações homo ou heterossexuais e pode ocorrer com contato físico, através de toques, caricias, penetrações e masturbações forçadas, como também pode ocorrer sem contato físico, através de assédio, pornografia, exibicionismo e voyeurismo (MIRANDA et al., 2019).

Segundo Souza, et al (2019), entre as maiores vítimas de abuso sexual estão as crianças e os adolescentes, uma vez que eles podem enfrentar mais dificuldades em resistir e denunciar. $\mathrm{Na}$ adolescência, que é caracterizada como a passagem da infância para a vida adulta, os adolescentes possuem uma maior vulnerabilidade e uma tendência a comportamentos de risco. Em virtude de não alcançarem uma maturidade cerebral, os sujeitos estão expostos a diversos riscos, como gravidez não planejada, infecções sexualmente transmissíveis e atos de violência, entre eles o abuso (PAPALIA; FELDMAN, 2013). Além dos riscos muito presentes na adolescência, vale ressaltar que os estilos parentais, isto é, o conjunto de práticas educativas utilizadas pelos pais ou cuidadores, podem influenciar no desenvolvimento cognitivo, afetivo e social de crianças e adolescentes de 
diferentes formas e intensidades, podendo contribuir ainda mais para uma maior vulnerabilidade em situações de risco (LANDI, 2019).

Além disso, é evidente que o abuso é um fenômeno complexo e como qualquer outra forma de violência sexual, é um ato que ocasiona dano demonstrável ou potencial ao indivíduo. Nesse sentido, o abuso sexual pode gerar implicações na saúde mental dos adolescentes (AZEVEDO; GUERRA, 1988). De acordo com Fontes; Conceição; Machado (2017), os adolescentes abusados têm elevado risco de desenvolver uma série de transtornos biopsicossociais, com repercussões sobre as esferas física, comportamental e cognitiva. Dessa forma, o presente estudo visa apresentar uma discussão sobre os efeitos do abuso sexual na saúde mental dos adolescentes e suas relações com os estilos parentais. Sendo assim, tem-se o presente problema de pesquisa: quais são os efeitos do abuso sexual na saúde mental dos adolescentes e suas relações com os estilos parentais?

A escolha da violência sexual como temática desse artigo surgiu a partir do fato que essa problemática social já esteve presente na sociedade em outras épocas, bem como causa sequelas psíquicas e sociais, que acabam por diminuir a qualidade de vida dos adolescentes. Dessa forma, esse artigo possui um tema de extrema importância para a área da Psicologia, uma vez que é crucial oferecer às vítimas uma oportunidade de escuta e acolhimento, que pode ser realizado com eficácia pelos profissionais da Psicologia. Portanto, os estudos a respeito desse tema são necessários com o objetivo de proporcionar cada vez mais debates nessa área, o que auxilia na criação de medidas preventivas e de promoção de saúde mental para o público adolescente. Além disso, possuindo o conhecimento que os estilos parentais possuem relações com a prevalência de sofrimento de abuso sexual, nota-se a importância do estudo no viés de orientação e supervisão de pais. Sendo assim, estudar esses aspectos também é importante para ampliar as pesquisas a respeito desse tema, bem como proporcionar um maior número de projetos de intervenção e prevenção junto aos jovens, seus pais e sua comunidade escolar.

Diante disso, o objetivo geral deste trabalho é verificar os efeitos do abuso sexual na saúde mental dos adolescentes e suas relações com os estilos parentais. Sendo assim, o presente estudo tem como objetivos específicos identificar na literatura os efeitos do abuso sexual nos aspectos emocionais e sociais dos adolescentes, bem como elucidar a relação dos estilos parentais com a maior predisposição de certos adolescentes de sofrerem abuso sexual.

\section{METODOLOGIA}

A pesquisa possui características de natureza básica, a qual visa contribuir com novos conhecimentos para a ciência sem aplicações práticas, apresenta a abordagem qualitativa, não necessitando de métodos e técnicas estatísticas. Tendo isso em vista, torna-se evidente que "tal pesquisa é descritiva. Os pesquisadores tendem a analisar seus dados indutivamente. O processo e seu significado são os focos principais da abordagem". Além disso, os fins de pesquisa definem o presente 
estudo com caráter exploratório, uma vez que visa propiciar mais informações a respeito do abuso sexual (PRODANOV; FREITAS, 2013, p. 70).

A análise bibliográfica foi realizada no período entre setembro e outubro de 2020. Durante esse tempo, foram selecionados artigos científicos, monografias e dissertações nacionais em plataformas online como Scielo, BVS, PubMed e Google Acadêmico, bem como foram utilizados capítulos de livros. Para a análise dos dados coletados foi utilizado o método da análise de conteúdo, formulada por Laurence Bardin, a qual caracteriza-se por uma pré-análise dos materiais, visando identificar o que já está disponível e o que ainda precisa ser pesquisado. Posteriormente, o material deve ser explorado, codificado, enumerado e categorizado, para por fim os resultados serem tratados e interpretados (BARDIN, 2006). Dessa forma, para o estudo ter sido realizado com eficácia, foram utilizados os descritores "violência sexual, jovens, bem-estar mental, práticas parentais".

\section{RESULTADOS E DISCUSSÕES}

\section{ADOLESCÊNCIA}

No Brasil, o Estatuto da Criança e do Adolescente (ECA), Lei 8.069, de 1990, considera criança a pessoa até 12 anos de idade incompletos e define a adolescência como a faixa etária de 12 a 18 anos de idade (BRASIL, 1990). A adolescência é uma época de descobertas, caracterizada geralmente pela busca de autonomia. Na maioria das sociedades modernas, a passagem da infância para a vida adulta é marcada por um longo período conhecido como adolescência, a qual consiste em uma transição no desenvolvimento físico, cognitivo, emocional e social do indivíduo, todavia, essas mudanças estão inseridas em um contexto social, cultural e econômico (PAPALIA; FELDMAN, 2013).

As características mais marcantes dessa fase consistem na busca da identidade, tendência grupal, desenvolvimento do pensamento abstrato, variação de humor, evolução da sexualidade e separação gradativa dos pais. Estas características são responsáveis não só pela construção de um indivíduo pleno, mas também para uma maior vulnerabilidade destes jovens (LANDI, 2019).

Segundo Papalia e Feldman (2013) a adolescência é compreendida como uma construção social, haja vista que tal conceito não existia nas sociedades pré-industriais. Dessa forma, as crianças eram consideradas adultas quando amadureciam fisicamente ou iniciavam um aprendizado profissional. Foi apenas no século XX que a adolescência foi definida como um estágio de vida separado no mundo ocidental.

O cérebro do adolescente ainda não alcançou sua maturidade, assim, é possível observar mudanças nas estruturas cerebrais envolvidas nas emoções, no julgamento, organização do comportamento e autocontrole. A propensão para comportamento de risco parece resultar da interação tanto da rede socioemocional que é sensível a estímulos sociais e emocionais - como a influência dos 
pares - quanto a rede de controle cognitivo que regula as respostas a estímulos. Dessa forma, a rede socioemocional torna-se mais ativa na puberdade, enquanto a rede de controle cognitivo amadurece mais gradualmente até o início da idade adulta. Devido a isso, é possível identificar uma maior vulnerabilidade e tendência a comportamento de risco nos adolescentes (PAPALIA; FELDMAN, 2013). Diante disso, tal imaturidade pode ser compreendida como um possível fator de risco ao abuso sexual.

\section{O ABUSO SEXUAL E SEUS FATORES DE RISCO}

Sendo considerado como a segunda forma de violência mais recorrente contra crianças e adolescentes, o abuso sexual é definido como qualquer ação de interesse sexual de um adulto contra uma criança ou adolescente (FLORENTINO, 2015). Esse tipo de violência é baseado no aproveitamento da relação de poder, afeto e confiança que o abusador tem sobre a criança e/ou adolescente. Nesse sentido, as crianças e os adolescentes são utilizado s para satisfazer as necessidades sexuais do abusador, obrigando-os a atos ou jogos eróticos e sexuais através de ameaças, subornos e violência, uma vez que a maioria das crianças e adolescentes possuem maiores dificuldades em resistir e denunciar (SOUZA et al., 2019).

O abuso sexual pode incluir toques, carícias, relações com penetração (oral, vaginal ou anal), masturbações forçadas, dentre outros. Além disso, também pode ocorrer sem o envolvimento de contato físico, como o voyeurismo, isto é, espionagem da nudez de uma criança ou adolescente, assédio, exposição a imagens ou eventos sexuais, pornografia e exibicionismo (AZEVEDO; GUERRA, 1988). Nesse sentido, observa-se que o abuso pode se expressar de diversas maneiras, uma vez que pode ocorrer com ou sem o uso da força e da violência.

Dependendo do contexto da ocorrência, existem diferentes categorias que podem definir o abuso. Entre as categorias está o abuso intrafamiliar, o extrafamiliar e o institucional. O abuso intrafamiliar ou incestuoso ocorre no âmbito familiar e é perpetrado por pessoas que tenham laços afetivos e que, geralmente, desempenham um papel de cuidador ou de responsável pela vítima. Há também o abuso extrafamiliar, que ocorre fora do ambiente familiar e envolve situações nas quais o agressor não possui parentesco, podendo tanto ser um desconhecido, como também alguém que a criança conheça e confie. E por fim, há o abuso institucional, na qual ocorre em instituições que são responsáveis por oferecer cuidados substitutivos aos da família para crianças e adolescentes (SAYÃO, 2006).

Na maioria dos casos, o abuso sexual ocorre dentro de casa, em um ambiente em que a criança deveria, supostamente, sentir-se protegida. Segundo o Centro Regional de Atenção aos Maus-Tratos na Infância de Campinas (SP), cerca de 90\% dos casos de abuso sexual acontecem no ambiente familiar, sendo o abusador alguém com quem a vítima convive, como o pai, o padrasto, tios, avós, irmãos ou vizinhos (ABRAPIA, 2002). Com isso, o abusador se aproveita da relação de poder sobre a vítima, tanto do ponto de vista hierárquico e econômico, quanto do ponto de vista afetivo (SANTOS, 2009). 
Desse modo, nessas situações, o ocorrido é mantido em segredo, dificultando que o crime venha à tona e seja notificado às autoridades.

De acordo com Fontes; Conceição; Machado (2017) existem alguns jovens que possuem comportamentos, bem como aspectos psicológicos e sociais que podem torná-los mais vulneráveis ao abuso sexual. Dessa forma, os efeitos de tal violência estão ligados a fatores pertencentes aos adolescentes, como a vulnerabilidade e a resiliência, as quais constituem-se pelo temperamento e pelo desenvolvimento neuropsicológico, bem como também está atrelado a fatores de risco e de proteção, como recursos sociais, modos de funcionamento familiar, recursos emocionais dos responsáveis e recursos financeiros. Portanto, fica nítido que certas consequências negativas do abuso sexual são acentuadas em indivíduos que não possuem uma rede de apoio afetiva (BRITO; KOLLER, 1999), uma vez que tais adolescentes acabam tornando-se mais vulneráveis e suscetíveis levando em conta que não possuem mecanismos preventivos para características desadaptativas. Tendo isso em vista, nota-se que a vulnerabilidade acentua os efeitos negativos das situações estressantes, contudo, também torna alguns sujeitos resilientes, uma vez que estes desenvolvem a capacidade de enfrentar adversidades de modo eficaz. Estes serão capazes de afrontar as situações conflituosas de suas vidas, pois suas características individuais foram somadas com a complexidade do contexto social, gerando a capacidade de resiliência (MORAIS; KOLLER, 2004).

É a partir desses fatos que nota-se a existência de muitos indivíduos que sofreram violências sexuais e não apresentaram grandes sequelas psicológicas, isso se deve a um conjunto de fatores protetivos responsáveis por gerar a resiliência. Em contrapartida, existe um grande número de jovens que sofrem constantemente com as consequências dos abusos, visto que eram indivíduos mais vulneráveis e ausentes de alguns aspectos de proteção. Contudo, deve se atentar que esses fatos não configuram-se como regras explícitas, uma vez que tudo depende da individualidade, do contexto e do ambiente do sujeito. Portanto, esses aspectos elucidam a importância de proteger e acolher os jovens adolescentes, bem como propiciar a eles uma boa e ampla rede de apoio, em que seja depositada confiança e honestidade. Dessa forma, tais indivíduos possuirão meios de proteção para o abuso sexual, minimizando as chances de serem vítimas e de sofrerem sequelas psíquicas.

Os autores analisam que algumas predisposições ao abuso sexual caracterizam-se por fazer parte da rotina e da configuração familiar. Tendo isso em vista, nota-se que a falta de supervisão dos pais configura-se como um fator de risco, uma vez que os cuidadores que possuem conhecimento a respeito do que seus filhos fazem em seu tempo livre estão criando indivíduos que possuem 50\% menos oportunidades de serem abusados sexualmente (FONTES; CONCEIÇÃO; MACHADO, 2017).

Contudo, é necessário atentar-se que em certos casos a própria família pode desencadear os episódios de abuso sexual, inibindo o processo de denúncia e tornando a violência persistente. Dessa forma, é papel crucial do psicólogo compreender a singularidade de cada vítima, bem como de sua estrutura familiar durante a escuta e acolhimento, uma vez que em alguns casos residir com os pais 
caracteriza-se como fator de proteção e em outros como fator de risco. Também nesse contexto, é possível notar que a pandemia de COVID-19 tornou os jovens mais vulneráveis ao abuso sexual intrafamiliar, devido ao isolamento domiciliar junto aos seus próprios abusadores. Portanto, a educação domiciliar dificultou o pedido de ajuda dessas vítimas, uma vez que não estão indo à escola e não possuem contato direto com o professor. Sendo assim, é nítido que certas situações de vulnerabilidade presentes nos contextos familiares podem acentuar os riscos dos adolescentes sofrerem abusos. Desse modo, famílias que são configuradas de modo violento e com extrema pobreza possuem maior tolerância social a esse tipo de abuso, uma vez que esses adolescentes possuem preocupações com a satisfação de suas necessidades básicas, como alimentação e moradia (SOUZA et al, 2019).

Desta maneira, encaixam-se nesse perfil os adolescentes em situação de rua, os quais muitas vezes saem de casa visando fugir de episódios de violência e extrema miséria. Como consequência, encontram na rua melhores condições de moradia do que na própria casa, contudo, acabam sendo vítimas de abuso e exploração sexual, uma vez que enxergam na prostituição meios de subsistência. Além das violências sexuais, esses jovens também acabam sofrendo inúmeras agressões físicas e psicológicas, como também sentem constante fome. Todas essas características minimizam drasticamente a qualidade de vida desses sujeitos, bem como abalam profundamente a saúde mental deles.

Esses fatores podem ser comprovados analisando as situações sociais atuais, levando em conta que adolescentes que possuem boas condições de vida, uma família ativa e afetiva e que recebem uma escolarização de qualidade são menos expostos a situações de vulnerabilidade. Em contrapartida, os indivíduos que não possuem esses aspectos, os quais vivem em situações de marginalidade e pobreza são mais prováveis de se depararem ao longo da vida com situações de fragilidade e indefesa. Além disso, em grande parte das vezes os adolescentes que vivem em regiões extremamente pobres não possuem acesso à escolaridade, o que os priva de adquirir conhecimentos a respeito de seus direitos e de sua sexualidade. Portanto, muitas vezes esses jovens são abusados pelos próprios pais dentro de casa e não possuem ferramentas para pedir ajuda, bem como não possuem conhecimento de que estão sofrendo uma violência. A partir disso, nota-se a importância do estudo da sexualidade como fator protetor ao abuso sexual, uma vez que ao ensinar aos jovens sobre seus direitos do próprio corpo, muitos casos de violência sexual infanto juvenil seriam percebidos e relatados.

Dessa forma, os adolescentes que são vítimas sexuais possuem maiores chances de terem utilizado drogas ilícitas e álcool, assim como terem amigos que já experimentaram também. Souza, et al (2019) explica isso pelo fato que o abuso dessas substâncias podem gerar alterações comportamentais nos adolescentes, aumentando a vulnerabilidade e os riscos de exposição à violência, como também reduzindo a percepção da realidade. Além disso, tais indivíduos possuem duas vezes mais chances de terem sofrido bullying no ambiente escolar, bem como maior probabilidade de defasagem de idade e série, menores possibilidades de estudarem além do ensino fundamental e maiores oportunidades para começarem a trabalhar mais cedo. Ademais, outros fatores como se o jovem pratica exercícios, 
o número de pessoas que residem na casa, se a mãe do adolescente fuma, se o jovem pratica exercícios fora da escola, se mora com a mãe ou se já sentiu fome em casa contribuem para aumentar o potencial risco de abuso sexual (FONTES; CONCEIÇÃO; MACHADO, 2017).

$\mathrm{O}$ autor afirma que o contexto virtual e midiático configura-se como um importante ambiente de risco, visto que os adolescentes são ingênuos para lidar com pessoas desconhecidas. Além disso, o ato de procurar relacionamentos em plataformas virtuais pode estar associado a estruturas familiares disfuncionais. Desse modo, os jovens acabam aderindo aos meios digitais como uma estratégia para a autoafirmação individual. A partir disso, o autor salienta a importância dos pais em orientar, supervisionar e educar seus filhos a respeito dos perigos das redes sociais, visando proteger os adolescentes de diversos tipos de violências (SOUZA; et al, 2019).

Ademais, é preciso ressaltar que a pandemia de COVID-19 deixou os jovens mais expostos a abusos sexuais virtuais, uma vez que eles estão expostos à internet por um tempo maior e em grande parte das vezes, sem supervisão parental. Dessa forma, nota-se que as redes sociais são responsáveis por expor cada vez mais a vida dos adolescentes, os quais possuem suas informações e fotos pessoais expostos de modo público. Tendo isso em vista, percebe-se que tais jovens são cada vez mais assediados virtualmente por indivíduos mais velhos, produzindo maiores chances de um abuso sexual ser efetivado com esse adolescente. Portanto, cabe enfatizar a importância dos pais monitorarem a rede social de seus filhos, bem como atentarem-se quanto ao compartilhamento fotos de crianças em suas redes, uma vez que com essa atitude, práticas de pornografia e abuso sexual infantil podem ser evitadas.

\section{OS EFEITOS DO ABUSO SEXUAL NA SAÚDE MENTAL DOS ADOLESCENTES}

A violência sexual contra o adolescente é um problema universal que atinge milhares de vítimas de forma silenciosa. Trata-se de um problema que acomete ambos os sexos e não costuma seguir nenhum critério como nível social, econômico, religioso ou cultural (CUNHA; SILVA; GIOVANETTI, 2008). Dessa forma, caracteriza-se por atos praticados com finalidade sexual que, por serem lesivos ao corpo e a mente do sujeito violado, desrespeitam os direitos e as garantias individuais como liberdade, respeito e dignidade previstos na Lei $\mathrm{n}^{\circ}$ 8.069/90 - Estatuto da Criança e do Adolescente (BRASIL, 1990, Artigos 7º 15, 16, 17 e 19).

Para Furniss (1993) ao debater as consequências do abuso sexual juvenil, é necessário considerar algumas particularidades que envolvem a violência praticada, como por exemplo, o grau de penetração, acompanhamento de insultos ou violência psicológica, uso de força ou violência física, entre outras brutalidades que são variações que comprometem as conclusões sobre as consequências do abuso sexual. Dessa forma, as consequências para quem sofre abuso sexual na adolescência dependem dos recursos psíquicos próprios de cada indivíduo. Estes são estabelecidos a partir da 
interação entre a vivência pessoal, fatores hereditários, identificação e modelo familiar. Contudo, há um consenso de que o abuso sexual representa um grande impacto na vida da vítima.

É possível identificar uma divisão por faixa etária dos impactos do abuso sexual, em adolescentes de 13 a 18 anos, observa-se a depressão, o isolamento, o comportamento suicida, a autoagressão, as queixas somáticas, os atos ilegais, as fugas, o abuso de substâncias lícitas ou ilícitas e o comportamento sexual inadequado (AMAZARRAY; KOLLER, 1988). Assim, infere-se que o ato extremo de suicídio seja uma tentativa de cessar com a situação dolorosa de abuso tanto de fuga dessa conjuntura perniciosa quanto da memória que persiste em ser relembrada repentinamente pela vítima.

Segundo Alvin (1997) é observável, nos adolescentes que recorrem a um tratamento, importantes reações a curto prazo. Elas são denominadas pelo choque, pela inibição e, sobretudo, pelo medo. Ademais, constata-se com regularidade reações fóbicas persistentes e, às vezes, muito seletivas, somatizações variadas, passagem depressiva ou regressiva, modificações do estilo de vida, sentimento de insegurança e culpa auto imposta. As consequências, a longo prazo, trata-se de tipos de fobias persistentes, acesso de angústias circunstanciais, de sonhos sobre o abuso, distúrbio do comportamento alimentar, de problemas com a imagem corporal e problemas de ordem relacional e sexual.

As experiências sexuais após o abuso sexual tendem a ser conflituosas para a vítima, frequentemente, interrompido por memórias vivenciadas na agressão. Compreendido, assim, como lapso de corpo morto, de um descompasso entre o desejo no nível mental e ausência de prazer ou repulsa experimentada simultaneamente. Dessa forma, é provável que a vítima de abuso sexual presencie dificuldades de vivenciar um relacionamento amoroso futuro.

Além disso, segundo Rouyer (1997) são frequentes o surgimento, principalmente nas adolescentes do sexo feminino, de problemas relacionados a alimentação - náuseas, vômito, anorexia e bulimia-, que assumirão, em seguida, outro significado, a saber, a recusa da feminilidade e a destruição do corpo. Nesse estado, esses transtornos alimentares podem ser fenômenos de rejeição e de compensação transitória.

\section{AS RELAÇÕES DO ABUSO SEXUAL COM OS ESTILOS PARENTAIS}

Os estilos parentais são o agrupamento de práticas educativas e atitudes parentais, as quais são utilizadas pelos responsáveis com o intuito de educar e controlar o comportamento das suas crianças, de modo que os comportamentos inadequados sejam extintos e os adequados reforçados. Entre os fatores que constituem os estilos parentais estão os aspectos de interação, como o tom da voz, a linguagem corporal, as mudanças de humor, o descuido e o cuidado no processo educacional e a socialização com os filhos. Tais modelos educativos podem interferir de modo negativo ou positivo nos aspectos cognitivos, sociais e autônomos do adolescente, como também podem influenciar na autoconfiança e na autoestima desse sujeito. Dessa forma, algumas representações parentais podem aumentar as taxas de vulnerabilidade para situações de risco entre os jovens. 
As práticas educativas estão vinculadas a fatores de desenvolvimento psicológico e comportamental da adolescência, como autoestima, depressão, ansiedade, desempenho acadêmico, competência interpessoal, comportamentos agressivos e autonomia. A partir disso, nota-se que há uma relação entre os estilos parentais não protetores e a maior vulnerabilidade para comportamentos antissociais, hiperatividade, impulsividade, uso e abuso de álcool, comportamentos sexuais de risco, idade de início da atividade sexual, múltiplos parceiros sexuais, sexo desprotegido, ISTs e gravidez na adolescência. Tendo isso em vista, esses adolescentes tornam-se mais inseguros e menos autoconfiantes, possuindo maiores chances de serem acometidos por abusos sexuais.

Alguns fatores familiares são importantes para indicar a possibilidade de ocorrência de abuso sexual em adolescentes. Para o autor, as famílias dos sujeitos abusados podem ser caóticas, violentas, conflituosas, bem como podem possuir pais separados, pobre vínculo afetivo entre os configurantes familiares, abuso de drogas e presença de psicopatologia em algum dos pais. Landi enfatiza que esses fatores não são determinantes para o abuso sexual, mas sim que aumentam a predisposição de tais indivíduos serem vítimas (LANDI, 2019). Sendo assim, fica nítido que a relação entre pais e filhos é um aspecto crucial para proteger os jovens de violências sexuais. Os pais que monitoram seus filhos, que possuem conhecimento a respeito dos locais que eles frequentam, que sabem quem são seus amigos e quais são as atividades extracurriculares que eles praticam estão criando indivíduos com mais mecanismos de proteção ao abuso sexual. Além disso, os pais que vigiam o uso de internet dos jovens também estão desenvolvendo sujeitos com menos riscos de serem vítimas.

Isso pode ser exemplificado na fala de Rouyer, a qual exemplifica que o incesto pode ser sintoma da disfunção presente na família da vítima, pois existe uma distorção de papéis e gerações familiares. Nesses casos, a criança sofre de carência afetiva, uma vez que ela é uma possessão de seus pais, e não um indivíduo dotado de direitos, portanto, torna-se mais vulnerável aos abusos. Além disso, a autora exemplifica casos de crianças carentes de afeto, as quais são influenciadas por adultos pedófilos, uma vez que estes são afetuosos e atenciosos, ao contrário dos próprios pais da vítima (ROUYER, 1997).

Tais crianças configuram-se dessa forma pois não recebem zelo e carinho de seus próprios pais, são indivíduos descuidados, que não são ouvidos e monitorados. A partir disso, torna-se muito mais fácil delas serem vítimas sexuais, isso porque aceitam qualquer forma de atenção. Na maioria das vezes elas não possuem orientações a respeito dos direitos que possuem sobre o próprio corpo, ou seja, não conhecem quais são as suas áreas corporais que não podem ser tocadas por ninguém. Esse grupo de indivíduos pode também caracterizar-se por não entender que este ato trata-se de uma violência. Isso se deve ao fato que os pais não ensinam sexualidade para suas crianças, bem como não as orientam sobre o que deve ser feito em situações de vulnerabilidade e angústia. Dessa forma, segundo Landi (2019) é de extrema importância identificar, supervisionar e aconselhar as famílias que configuram-se de forma desequilibrada. Portanto, essa tarefa pode ser realizada através do estudo dos estilos parentais, visando minimizar riscos para os jovens. 
Os estilos parentais configuram-se a partir do estilo participativo, do estilo autoritário, do estilo permissivo e do estilo negligente. Dessa forma, o modelo parental participativo constitui uma parentalidade baseada no cuidado e no controle. Sendo assim, os pais participativos educam seus filhos com empatia e compreensão, estabelecendo uma comunicação aberta e respeitosa, de modo que as orientações sejam claras e consistentes, bem como um suporte emocional seja realizado. A partir dessa elucidação, fica claro que esse modelo parental é o mais saudável, visto que equilibra o cuidado e o controle. As crianças são orientadas de forma didática, sem xingamentos ou pressões psicológicas e não são agredidas fisicamente. Dessa forma, os pais são indivíduos de confiança para esses jovens, o que os protege efetivamente contra a violência sexual, uma vez que eles podem contar com o apoio e a orientação parental.

Em contrapartida, os pais autoritários possuem um grande rigor com o comportamento dos seus filhos, dessa forma, eles utilizam diversas práticas punitivas e possuem pouca empatia. Na grande maioria das vezes são pais muito exigentes e não dispõem de suporte emocional para os jovens, proporcionando um distanciamento entre eles. Esses adultos agridem física e psicologicamente os adolescentes, de forma que não exista um local de escuta e acolhimento para eles. Em virtude disso, esses jovens acabam não confiando em seus próprios pais, o que os torna mais vulneráveis para situações de violência sexual, uma vez que não possuem uma rede de apoio saudável dentro de casa.

Além disso, existem os pais permissivos, os quais beneficiam todas as vontades dos filhos e não impõem limites e orientações. Esse modelo parental pode constituir pais ausentes que sentem culpa, desse modo, visam compensar seus filhos por conta disso, como também podem ser cuidadores que sentem medo de não serem aceitos pelos próprios filhos. Tal definição é facilmente compreendida e assimilada, visto que nos grupos sociais é possível identificar um grande número de pais que acabam sendo governados pelos filhos. Nesses casos, os jovens acabam comandando a relação e podem fazer tudo o que tem direito. Além disso, quando os responsáveis contrariam os filhos e negam suas vontades, esses acabam sendo se desculpando e voltando atrás sobre suas escolhas.

Por fim, a autora elucida a respeito dos pais negligentes, estes dispõem de pouco suporte e controle para os jovens, bem como passam pouco tempo com eles (MACANA; COMIN, 2015). Esses cuidadores não são responsivos, não aceitam suas responsabilidades, ignoram os comportamentos dos filhos e não possuem iniciativa de comunicação (GOMIDE, 2014). Também é possível observar essa parcela de responsáveis na sociedade, uma vez que são aqueles pais que não comparecem à escola dos filhos, seja para reuniões, apresentações ou atividades escolares. Como também quase nunca estão disponíveis para os jovens, visto que trabalham demais e não possuem tempo para a parentalidade. Essas crianças acabam sendo afastadas dos seus pais, de modo que crescem sem nenhuma forma de amparo e zelo por parte destes, o que contribui ativamente para tornarem-se muito mais vulneráveis ao abuso sexual.

Tendo isso em vista, filhos de pais negligentes podem sofrer com déficits comportamentais, uma vez que são educados de forma passiva na infância. Dessa forma, a falta de carinho na interação entre 
pais e filhos pode gerar sentimentos de insegurança, vulnerabilidade e hostilidade nos jovens, contribuindo para uma maior prevalência de violência sexual em relacionamentos íntimos nessa parcela social. Além disso, em grande parte das vezes os pais negligentes não notam os sinais do abuso sexual infanto juvenil, uma vez que não se dedicam efetivamente aos seus filhos e não os proporcionam momentos de escuta e atenção. Portanto, o autor argumenta que as práticas parentais que caracterizam-se pelo afeto e carinho configuram-se como fator protetor ao abuso sexual entre os adolescentes.

Além disso, filhos de pais autoritários possuem maiores chances de desenvolverem depressão, ansiedade, retração social e comportamentos agressivos. Como também podem não aprimorar suas habilidades sociais e possuírem baixa autoestima. Desse modo, tais adolescentes possuem maiores riscos de serem vítimas de abuso sexual. Em contrapartida, os responsáveis que educam seus filhos a partir do modelo parental participativo desenvolvem adolescentes com maior autoestima, autoconfiança e autonomia. Tendo isso em vista, esses indivíduos possuem melhores mecanismos para enfrentar situações de adversidade, configurando esse modelo parental como um fator de proteção para o abuso sexual.

Portanto, o autor enfatiza que pais afetuosos, os quais zelam pelos filhos e são pouco autoritários criam indivíduos mais resilientes, autoconfiantes e autônomos, dessa forma, mesmo se eles forem vítimas de violências sexuais, possuirão menos riscos de desenvolverem alguma desordem psíquica (LANDI, 2019). Dessa forma, é evidente que o monitoramento parental é crucial, portanto, os pais devem se informar sobre a vida dos filhos, visto que isso os protege efetivamente. É importante destacar que uma forma de guiar os indivíduos sobre esse assunto é ensinar sobre pedir ajuda, ou seja, os pais devem esclarecer aos filhos que se algo acontecer com eles, deve ser comunicado aos responsáveis. Para que isso seja feito, é importante que os adultos estabeleçam vínculos de confiança com os adolescentes, só assim esses jovens possuirão o apoio e a proteção necessária contra os abusos sexuais.

\section{ABORDAGENS DE PREVENÇÃO AO ABUSO SEXUAL EM ADOLESCENTES}

Conforme mencionado anteriormente, crianças e adolescentes vítimas de abuso sexual costumam apresentar alguns sinais e certas mudanças em seu comportamento. Nesse sentido, é de extrema importância que os pais, responsáveis ou educadores estejam atentos e saibam identificar situações de abuso sexual (SANTOS, 2009).

É muito difícil ensinar às crianças e aos adolescentes a identificarem os fatores de risco dos abusos sexuais. No entanto, torna-se essencial ensiná-las a dizerem não, a buscarem ajuda e escaparem quando identificarem comportamentos manipuladores de adultos. Segundo Sayão, é importante que as crianças e os adolescentes tenham noções dos limites que devem saber em relação a terem seus corpos tocados por outras pessoas. Nesse sentido, ressalta-se a importância de promover a consciência da criança e do adolescente de que seu corpo pertence somente a si mesmo e que só deverá ser tocado por outra pessoa com o seu consentimento ou por razões de saúde e higiene. 
Nesse contexto, é fundamental que a Educação Sexual seja tratada no ambiente familiar, pois crianças e adolescentes que têm pais/mães ou responsáveis que conversam sobre o assunto, informam e tiram as dúvidas sobre seu corpo, desenvolvimento físico, higiene, saúde e bem-estar estão mais aptas a se protegerem de situações de abuso sexual. Sendo assim, é importante que o adolescente, desde criança, tenha o conhecimento sobre o que é sexo, que relação sexual não é praticada por crianças e da existência do abuso sexual, para que desta forma, possa evitar situações, ter o poder de enfrentamento e a confiança em denunciar e estar assegurada (MIRANDA; OLIVEIRA, 2013).

Um dos fatores de proteção que pode diminuir o abuso sexual é a existência de apoio individual e/ou institucional para as vítimas (PADILHA, 2007). Sendo assim, a escola é um importante espaço para trabalhar a prevenção do abuso sexual contra crianças e adolescentes. A inclusão da Orientação Sexual nas escolas articula-se com a promoção da saúde de crianças, adolescentes e jovens, contribuindo para o aumento de chances da população infanto juvenil se proteger em situações de abuso. Nesse sentido, o trabalho possibilita a realização de ações preventivas das infecções sexualmente transmissíveis, do abuso sexual e da gravidez indesejada.

Além disso, ressalta-se ainda que o papel da escola e de outras instituições educativas é fundamental na prevenção do abuso sexual. Em situações que ocorrem o abuso intrafamiliar, muito provavelmente, serão os professores ou educadores que irão acolher e proteger o adolescente que tenha sido abusado. Dessa forma, é necessário que os educadores fiquem atentos às alterações no comportamento das crianças e adolescentes (SAYÃO, 2006).

É por meio da informação, educação e prevenção que podemos implementar estratégias de prevenção contra o abuso sexual de crianças e adolescentes, e também fortalecer uma rede de apoio para essa população. A informação e o conhecimento sobre o assunto permite uma melhor abordagem em casos de abuso sexual. Dessa forma, a fim de interromper o ciclo da violência, é essencial que profissionais das mais diferentes áreas que lidam com crianças e adolescentes estejam preparados e treinados para as diversas técnicas de reconhecimento de sinais de abuso sexual. Cabe ressaltar que, não se trata apenas de marcas físicas, mas também alterações no comportamento.

A identificação precoce das interações sexuais é de extrema importância para o tratamento e acolhimento de vítimas de abuso sexual. É essencial que os casos de suspeita de abuso sexual sejam notificados às autoridades e que eles priorizem o encaminhamento da criança e do adolescente ao serviço educacional, médico, psicológico. Desse modo, quanto antes a vítima receber apoio e atendimento, maiores as chances de superar essa experiência negativa e evitar que ela reproduza, quando adulta, o abuso sofrido na infância (SANTOS, 2009).

A revelação do abuso deve ser uma das prioridades dos programas de prevenção, a fim de evitar graves consequências para a saúde mental das crianças e dos adolescentes. É fundamental que os profissionais ouçam a criança e acreditem em tudo o que ela disser. Assim, eles receberão as revelações, levando em consideração a palavra da criança e do adolescente, pensarão em cuidados sociais, 
médicos e psicológicos e tomarão as medidas necessárias para reconhecerem e apontarem o abusador como culpado (BOUHET; PÉRARD; ZORMAN, 1997).

\section{CONSIDERAÇÕES FINAIS}

Tendo em vista que o objetivo do estudo consiste em verificar os efeitos do abuso sexual na saúde mental dos adolescentes e suas relações com os estilos parentais, é possível concluir que essas consequências a saúde mental dependem tanto do grau de violência sofrida quanto dos recursos psíquicos próprios do jovem. Todavia, há um consenso de que o abuso sexual representa um grande impacto na vida da vítima. Dessa forma, observa-se nos adolescentes vítimas do abuso o isolamento, a depressão, o comportamento suicida, as queixas somáticas, os atos ilegais, o abuso de drogas, o comportamento sexual inadequado, bem como o sentimento de insegurança e a culpa auto imposta.

Além disso, é relevante ponderar sobre o papel dos estilos parentais nessa circunstância. Nota-se que há uma relação entre os estilos parentais não protetores e a maior vulnerabilidade para comportamentos de risco, como por exemplo, a impulsividade, o uso e abuso de álcool, os comportamentos sexuais de risco. Diante disso, esses adolescentes tornam-se mais inseguros e menos autoconfiantes, possuindo maiores chances de serem acometidos por abusos sexuais. Além disso, as famílias dos sujeitos abusados podem ser violentas, conflituosas, bem como podem possuir pobre vínculo afetivo. Todavia, é relevante enfatizar que esses fatores não são determinantes para o abuso sexual, mas sim que aumentam a predisposição de tais indivíduos a serem vítimas. Portanto, práticas parentais que se caracterizam pelo afeto e carinho, ou seja, o modelo parental participativo, configuram-se como fator protetor ao abuso sexual entre os adolescentes.

Nesse sentido, torna-se pertinente refletir sobre os fatores de risco e de proteção que estão intimamente atrelados aos recursos sociais, modos de funcionamento familiar, recursos emocionais dos responsáveis, recursos financeiros, bem como uma rede afetiva de apoio. Dessa forma, compreende-se que a miséria configura um fator de risco ao abuso sexual. Ademais, fica claro que apenas o fato de ser mulher já se configura como fator de risco, visto que o sexo feminino é mais assediado, abusado e violentado. Além disso, o contexto virtual e midiático configura-se como um importante ambiente de risco, visto que os adolescentes são mais influenciáveis e ingênuos para lidar com pessoas desconhecidas. Diante disso, é fundamental que a Educação Sexual seja tratada tanto no ambiente familiar quanto no escolar, a fim de proporcionar recursos protetivos contra o abuso sexual juvenil.

Todavia, é relevante ponderar sobre os limites presente no estudo, na qual consiste, primeiramente, em uma pesquisa de natureza básica, em sua maior parte, na língua portuguesa o que limita, consideravelmente, a pesquisa sobre esse tema. Além disso, as fontes analisadas foram produzidas no ocidente que possibilitam um recorte da realidade significativo. Por fim, almeja-se com esse estudo o esclarecimento sobre os impactos do abuso sexual na saúde mental dos adolescentes, bem como 
seus fatores de risco e proteção. Dessa forma, a família, a comunidade e a escola possuem um papel fundamental na orientação e prevenção dessa violação contra os adolescentes. Nessa conjuntura, a educação sexual é uma aliada ao combate do abuso sexual juvenil.

\section{REFERÊNCIAS}

ABRAPIA - ASSOCIAÇÃO BRASILEIRA MULTIPROFISSIONAL DE PROTEÇÃO A INFÂNCIA E À ADOLESCÊNCIA. Abuso sexual - mitos e realidade. Petrópolis: Autores \& Agentes \& Associados, 3. Ed., Abrapia, 2002.

ALVIN, P. Os adolescentes vítimas de abuso sexual. In: GABEL, M. (Org). Crianças vítimas de abuso sexual. 2. ed. Tradução Sonia Goldfeder e Maria Carlotta Carvalho Gomes. São Paulo: Summus. p. $72-81.1997$

AMAZARRAY, M. R; KOLLER, S. H. Alguns aspectos observados no desenvolvimento de crianças vítimas de abuso sexual. Psicologia: Reflexão e Crítica, Porto Alegre, v. 11, n. 3. p. 559-579. 1998.

AZEVEDO, M. A; GUERRA, V. N. Pele de asno não é só estória... um estudo sobre a vitimização sexual de crianças e adolescentes em família. São Paulo: Editora Roca, 1988.

BARDIN, L. Análise de conteúdo. Tradução REGO, A; PINHEIRO, A. Lisboa: Edições 70, 2006. BOUHET, B; PERARD, D; ZORMAN, M. Da importância dos abusos sexuais na França. In: GABEL, M. (Org). Crianças vítimas de abuso sexual. 2. ed. Tradução Sonia Goldfeder e Maria Carlotta Carvalho Gomes. São Paulo: Sammus. p. 29-42. 1997

BRASIL. Presidência da República. Casa Civil. Subchefia para Assuntos Jurídicos. Lei no 8.069, de 13 de julho de 1990. Dispõe sobre o Estatuto da Criança e do Adolescente e dá outras providências. Diário Oficial da União, Brasília, DF, 1990.

BRITO, R. C; KOLLER, S. H. Redes de apoio social e afetivo e desenvolvimento. In: CARVALHO, A. M (Org). O mundo social da criança: Natureza e cultura em ação. São Paulo: Casa do Psicólogo, p. $115-130.1999$.

CUNHA, E. P; SILVA, E. M; GIOVANETTI, A. C. Enfrentamento à violência sexual infanto-juvenil: expansão do PAIR em Minas Gerais. Belo Horizonte: UFMG, 2008. 
FLORENTINO, B. R. B. As possíveis consequências do abuso sexual praticada contra crianças e adolescentes. Fractal: Revista de Psicologia, Minas Gerais, v. 27, n. 2. p. 139-144. 2015.

FONTES, L. F. C; CONCEIÇÃO, O. C; MACHADO, S. Violência sexual na adolescência, perifl da vítima e impactos sobre a saúde mental. In: Ciência e Saúde Coletiva, v. 22, n. 29. p. 2919-2928. 2017.

FURNISS, T. Abuso Sexual da Criança: uma abordagem multidisciplinar. Porto Alegre: Artes Médicas, 1993.

GOMIDE, P. I. C. Inventário de estilos parentais - IEP: modelo teórico, manual de aplicação, apuração e interpretação. $3^{\mathrm{a}}$ ed. Petrópolis, RJ: Vozes, 2014.

LANDI, C. A. Violência sexual contra adolescentes e adultos jovens e estilos parentais. Dissertação (Mestrado em Ciências). Universidade Federal de São Paulo (UNIFESP) -Escola Paulista de Medicina. Programa de Pós-Graduação em Saúde Coletiva. São Paulo. 2019.

MACANA, E. C; COMIN, F. O papel das práticas e estilos parentais no desenvolvimento da primeira infância. In: PLUCIENNIK, G. A; LAZZARI, M. C; CHICARO, M. F. (Orgs). Fundamentos da família como promotora do desenvolvimento infantil: parentalidade em foco. 1. ed. São Paulo: Fundação Maria Cecília Souto Vidigal (FMCSV). p. 34-48. 2015.

MIRANDA, A. T; OLIVEIRA, M. Abuso sexual infantil e escola: enfrentamento e intervenções pedagógicas. In: Anais. Seminário Internacional Fazendo Gênero 10: Florianópolis, 2013.

MIRANDA, M. H, et al. Violência sexual contra crianças e adolescentes: uma análise da prevalência e fatores associados. Rev Esc Enferm USP, São Paulo, v. 54, p. 1-8, 2019.

MORAIS, N. A; KOLLER, S. Abordagem ecológica do desenvolvimento humano, Psicologia positiva e resiliência: Ênfase na saúde. In: KOLLER, S (Org). Ecologia do desenvolvimento humano: Pesquisa e intervenção no Brasil. São Paulo: Casa do Psicólogo, p. 91-107. 2004.

PADILHA, M. Prevenção primária de abuso sexual: avaliação da eficácia de um programa com adolescentes e pré-adolescentes em ambiente escolar. 2007. 183 f. Tese (Doutorado em Ciências Humanas) - Universidade Federal de São Carlos, São Carlos, 2007. 
PAPALIA, D; OLDS, S; FELDMAN, R. Desenvolvimento humano. 12.ed. Porto Alegre: AMGH, 2013.

PRODANOV C. C; FREITAS E. C. Metodologia do Trabalho Científico: Métodos e Técnicas da Pesquisa e do Trabalho Acadêmico. In: Pesquisa Científica, cap. 3. $2^{\circ}$ ed. Universidade FEEVALE, Novo Hamburgo, Rio Grande do Sul, Brasil; 2013.

ROUYER, M. As crianças vítimas, consequências a curto e médio prazo. In: GABEL, M. (Org). Crianças vítimas de abuso sexual. 2. ed. Tradução Sonia Goldfeder e Maria Carlotta Carvalho Gomes. São Paulo: Summus. p. 62-72. 1997.

SANTOS, B. Guia de referência: construindo uma cultura de prevenção à violência sexual. São Paulo : Childhood - Instituto WCF-Brasil, 2009.

SAYÃO, Y. Refazendo laços de proteção: ações de prevenção ao abuso e à exploração sexual comercial de crianças e adolescentes: manual de orientação para educadores. São Paulo: CENPEC: CHILDHOOD - Instituto WCF-Brasil, 2006.

SOUZA V. P, et al. Fatores de risco associados à exposição de adolescentes à violência sexual. In: Av Enferm., Bogotá , v. 37, n. 3. p. 364-374. Dez 2019. 